\title{
Human Telomeric Quadruplex Conformations Studied by Pulsed EPR**
}

\author{
Vijay Singh, Mykhailo Azarkh, Thomas E. Exner, Jörg S. Hartig, * and Malte Drescher
}

Guanosine rich nucleic acids fold into four stranded struc tures called quadruplexes. ${ }^{[1,2]}$ The telomeric repeats at the end of the chromosomes, have generated much interest. In humans, they are composed of the hexameric GGGTTA repeat with the $3^{\prime}$ ends consisting of a 100 to 200 nucleotide single stranded overhang. ${ }^{[3]}$ As a result of their potential to switch between folded and unfolded state, the formation of quadruplex structures is suspected to play important roles in telomere maintenance and cell cycle control. ${ }^{[4,5]}$ In contrast to duplex structures, quadruplexes show a high degree of polymorphism with respect to topological features, such as the orientation of individual strands and the connectivity of the loops. For example, the human telomeric repeat is known to adopt drastically different conformations depending on parameters such as the type of monovalent ions coordinated by the quadruplex and the slight changes in the nucleotide sequence. $\left.{ }^{[6} 8\right]$

NMR spectroscopic and crystallographic studies have delivered impressive high resolution structures of human telomeric quadruplexes. Biophysical studies indicate similar stabilities of these structures and provide increasing evidence of the co existence of some of these folds under physiological conditions. Unfortunately, the high resolution methods are not able to decipher the exact nature of these structures under near physiological conditions since these techniques require the presence of single species. Biophysical methods such as circular dichroism (CD) spectroscopy are very informative but the results tend to be over interpreted ${ }^{[0]}$ and have produced controversial results recently as discussed below. Herein, we investigate quadruplex conformations under near physiological conditions utilizing double nitroxide modified telomeric sequences in combination with a two frequency pulsed electron paramagnetic resonance (EPR) method (Figure 1a). Double electron electron resonance (DEER or PELDOR) spectroscopy is ideally suited to distinguish between the different conformations since it allows distance

[*] Dr. V. Singh, ${ }^{[+]}$M. Azarkh, ${ }^{[+]}$Prof. Dr. T. E. Exner, Prof. Dr. J. S. Hartig, Dr. M. Drescher

Department of Chemistry, Konstanz Research School Chemical Biology (KoRS CB), and the Zukunftskolleg, University of Konstanz 78457 Konstanz (Germany)

E mail: joerg.hartig@uni konstanz.de

Homepage: www.uni konstanz.de/fuf/chemie/jhartig/

['] These authors contributed equally to this work.

$\left[*^{* *}\right]$ J.S.H. acknowledges the VolkswagenStiftung for funding a Lichten berg Professorship. This work was financially supported by the DFC (DR 743/2 1) and the Center for Mesoscopic Structures within the Exzellenzinitiative. EPR electron paramagnetic resonance.

(Q) Supporting information for this article is available on the WWW under http://dx.doi.org/10.1002/anie.200902146. a)

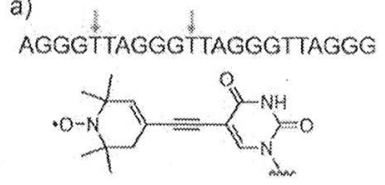

c)

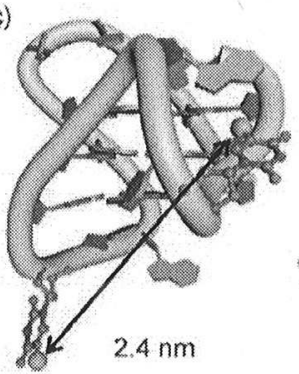

d)

b)

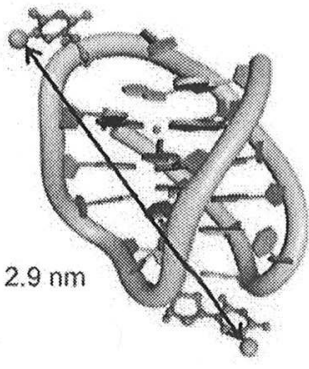

$(8)-5 \leq 28)$

$1.7 \mathrm{~nm}$

Figure 1. Human telomeric quadruplexes. a) Sequence examined in this study. Arrows indicate sites of 5 TEMPA modified deoxyuridine. b) d) Different intramolecular quadruplex topologies based on high resolution structures. Black arrows indicate distances measured between $\mathrm{C} 5$ methyl carbon atoms of deoxythymidine residues at positions indicated in (a) on the basis of the PDB structures. b) NMR spectroscopy structure of the antiparallel basket quadruplex in $\mathrm{Na}^{+}$ion containing solution (PDB: 143D) ${ }^{[10]} \mathrm{c}$ ) NMR spectroscopic structure of a hybrid $3+1$ quadruplex of a slightly modified sequence in $\mathrm{K}^{+}$ions (PDB: 2GKU). ${ }^{[1]} \mathrm{d}$ ) Crystal structure of the parallel propeller form in the presence of $\mathrm{K}^{+}$ions (PDB: 1KF1)..$^{12]}$

distributions ranging from 1.5 to $7.5 \mathrm{~nm}$ to be measured even in structurally heterogeneous systems. ${ }^{[13,14]}$ Prominent intra molecular quadruplex conformations of four repeat human telomeric sequences are summarized in Figure 1: In $\mathrm{Na}^{+}$ion containing buffers an antiparallel quadruplex resembling a basket conformation is found for the sequence $\mathrm{A}$ (GGGTTA) ${ }_{3}$ GGG. $^{[10]}$ Nevertheless, the picture gets more complicated in the presence of $\mathrm{K}^{+}$ion which is the more prevalent intracellular cation: For the same sequence the so called propeller form was found in a crystal structure with all strands in a parallel orientation. ${ }^{[12]}$ However, with sequences slightly modified at both ends, two forms of hybrid parallel/ antiparallel $3+1$ topologies with one loop oriented in a double chain reversal were recently described by three groups using NMR spectroscopic studies, see Figure $1 .^{[11,1517]}$ Interestingly, many studies have indicated that a mixture of different conformations exists in $\mathrm{K}^{+}$ion containing solutions. ${ }^{[8,18}{ }^{32]}$ Although several of these works agree upon the presence of an equilibrium of some antipar allel or hybrid $3+1$ form together with the parallel propeller form, a majority of studies report that the parallel propeller structure is not a dominant fold in $\mathrm{K}^{+}$ion containing 
solutions. $\left.{ }^{[18} 21,2629\right]$ In addition, the debate is fuelled by a considerable number of contradictory results: $\mathrm{CD}$ spectra of the sequence (GGGTTA) ${ }_{3}$ GGG and A(GGGTTA) ${ }_{3}$ GGG are interpreted as exclusively the antiparallel basket form with both $\mathrm{Na}^{+}$and $\mathrm{K}^{+}$ions. ${ }^{[2]]}$ Cross linking experiments using a platinum complexes indicate that for the sequences $\mathrm{A}$ (GGGTTA) ${ }_{3}$ GGG and (TTAGGG) ${ }_{4}$ the antiparallel basket form dominates for both ions. ${ }^{[28]}$ On the other hand a biophysical study of (TTAGGG) ${ }_{4}$ in $\mathrm{K}^{+}$suggests only the $3+1$ hybrid species as dominant form. ${ }^{[3]}$ Taken together it remains unclear which structure really contributes to the observed mixture since an unequivocal assignment by $\mathrm{CD}$ spectra alone is difficult and other methods are at least to some extent inconclusive. Herein we introduce spin label quadruplex EPR for investigating distance in the nanometer range and demonstrate the presence of a 1:1 mixture of the parallel propeller and antiparallel basket structures in $\mathrm{K}^{+}$ion solution.

Several approaches were used to incorporate spin labels into DNA or RNA sequences. ${ }^{[34}{ }^{37]}$ Besides mobility studies on DNA folding by conventional continuous wave (cw) EPR, ${ }^{[38]}$ pulsed DEER experiments were utilized to measure distances in DNA model systems. ${ }^{[14.34 .37,39,40]}$ We have synthe sized oligonucleotides spin labeled with TEMPA. ${ }^{[41}{ }^{43]}$ We chose to incorporate the spin labels at nucleotides 5 and 11 as depicted in Figure 1 a because measurements of the distance between these positions allows the different quadruplexes to be discriminated (for a comparison of predicted distances in all iterations of deoxythymidine positions see Supporting Information). $\mathrm{CD}$ spectroscopy was used to compare spin labeled with unmodified sequences both in $\mathrm{Na}^{+}$and $\mathrm{K}^{+}$ion solutions. Importantly, identical spectra were obtained for the labeled and unlabeled oligonucleotides, showing that the incorporation of the TEMPA groups did not change the quadruplex topologies (see Supporting Information Fig ure $\mathrm{S} 1$ ).

For DEER experiments, the DNA samples $(50 \mu \mathrm{m}$ oligo nucleotide concentration) were annealed in $\mathrm{Na}^{+}$or $\mathrm{K}^{+}$ solution. After shock freezing in liquid nitrogen to trap the annealed conformations they were measured at $45 \mathrm{~K}$ (for details see Supporting Information). Data were analyzed using DeerAnalysis2008. ${ }^{[44]}$ Model free analysis revealed that the spin label distance distributions can be characterized well by one or two Gaussian curves. Tikhonov regularization (see Supporting Information, Figure S4) as well as considering the root mean square (RMS) deviation of the Gaussian models enabled us to unambiguously distinguish whether one or two conformations are present. The presence of two conforma tions in $\mathrm{K}^{+}$ion also agrees with the findings frequently reported. $\left.{ }^{[8,18} 32\right]$

The width of the distribution (half width at half maximum $\leq 1 \mathrm{~nm}$ ) is caused by the flexibility of the spin labeled trinucleotide loops. The resulting distances discussed below correspond to the center of the Gaussian curves. The nitro xide labeled structures were modeled by energy minimizing in explicit solvents using specialized force field parameters for the label based on the AMBER force field. The distances derived from this modeling procedure are similar to the distances shown in Figure 1. However, molecular dynamics studies (carried out with spin labeled quadruplexes) indicate that the resulting distances of the minimized structures are not representative for the thermodynamic ensemble of the highly flexible loops. Therefore the distances used for assign ment were derived from the 5 methyl carbon atoms of the marked positions in the nucleotide (positions 5 and 11) taken from the protein data bank (PDB). Intermolecular quadru plex formation was excluded by measuring distances in single labeled sequences. These single labeled sequences were also used to assess the local mobility of the spin labels, which again indicated the high flexibility of the trinucleotide loops (see Supporting Information).

It is generally accepted that in $\mathrm{Na}^{+}$ion containing solutions the antiparallel basket form (Figure $1 \mathrm{~b}$ ) is the only conformation. ${ }^{[10]}$ In accordance with the distance $(2.9 \mathrm{~nm})$ between the spin labels as determined from the PDB coordinates, we found exclusively a single species with a distance of $(3.0 \pm 0.1) \mathrm{nm}$ by DEER, agreeing with the expectation of solely the basket conformation present (Fig ure $2 \mathrm{a}$ and $\mathrm{b}$ ). In contrast, in $\mathrm{K}^{+}$ion solution we found $\mathrm{a}$
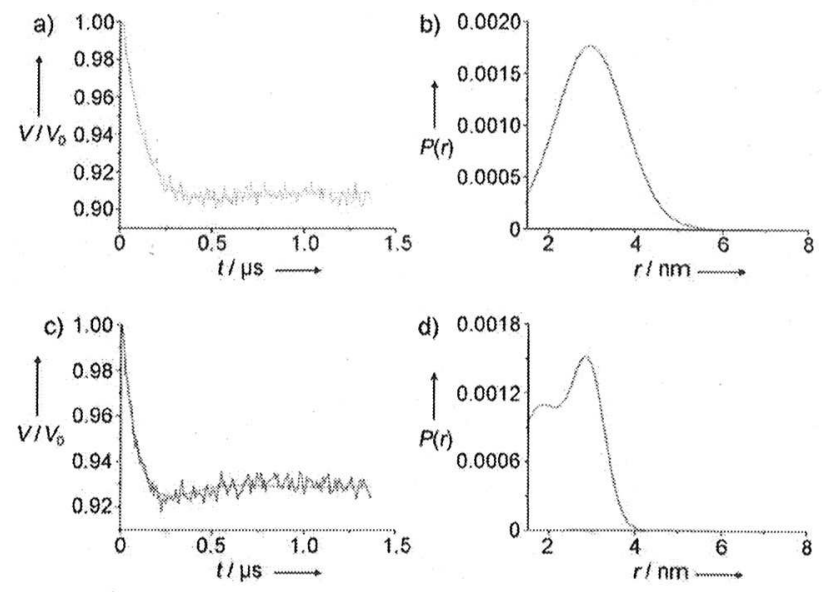

Figure 2. DEER spectroscopy data. Dipolar evolution after background correction for the $\mathrm{A}(\mathrm{GGGTTA}){ }_{3} \mathrm{GCG}$ sequence in the presence of $\mathrm{Na}^{+}$(a) and $\mathrm{K}^{+}$(c) solutions, respectively, with fitting curves assuming one or two Gaussians, respectively. Corresponding distance distribu tions reveal one conformer in $\mathrm{Na}^{+}$(b) and two distinct species in $\mathrm{K}^{+}(\mathrm{d})$ containing solutions.

mixture of two species. Fitting with only one broader Gaussian results in a significantly worse agreement with the experimental data, whilst using two Gaussians for Figure $2 b$ results in a single conformation as well. The two forms of quadruplexes in $\mathrm{K}^{+}$are present in relative intensities of 55 and $45 \%( \pm 6 \%)$. The first species is characterized by a distance of $(1.8 \pm 0.2) \mathrm{nm}$ corresponding to the expected value in the parallel propeller form (Figure $1 \mathrm{~d}$ ) whereas the second species has a distance of $(3.0 \pm 0.1) \mathrm{nm}$ identical to the results obtained in $\mathrm{Na}^{+}$ion solution (Figure $2 \mathrm{c}$ and d). Our measurements thus agree with the presence of the propeller and the basket quadruplex. To exclude a mistaken assignment of the distance measurements with the respective topologies, we synthesized an additional control oligonucleotide. The sequence TT(GGGTTA) ${ }_{3}$ GGGA slightly deviates from the 
original telomeric repeat but folds into the hybrid $3+1$ form in $\mathrm{K}^{+}$ion solution. ${ }^{[11,17]}$ The expected distance between the spin markers as obtained from the NMR spectroscopy structure (Figure 1c) is $2.4 \mathrm{~nm}$. Using the DEER method we measured a distance of $(2.6 \pm 0.1) \mathrm{nm}$ (see Supporting Information, Figure S3), a value in between those of the parallel propeller and the antiparallel basket, consolidating the observation for the propeller and basket forms in $\mathrm{K}^{+}$ solution for the sequence A(GGGTTA) $)_{3}$ GGG.

In conclusion, we have introduced EPR distance measure ments for the investigation of highly polymorphic DNA quadruplexes. In contrast to frequent hypotheses we find a 1:1 distribution of both the all parallel propeller and the all antiparallel basket form for the telomeric repeat investigated. Nevertheless, we cannot rule out the significance of the $3+1$ hybrid form since it has been shown that its presence is favored in sequences bearing additional nucleotides flanking the core sequence necessary for quadruplex formation. In this respect, the presented method should prove valuable for the observation of quadruplexes in much longer sequence con texts as well as in ensembles containing other molecules. Since the observation of a given quadruplex in presence of excess nucleic acids, proteins, or small molecules is often trouble some using methods such as $\mathrm{CD}$ spectroscopy, the utilization of pulsed EPR methods should prove especially useful for addressing structural features in more complex systems.

ywords: DEER spectroscopy - DNA quadruplexes . human telomeres - nucleic acid conformations - spin labeling

[1] J. R. Williamson, Annu. Rev. Biophys. Biomol. Struct. 1994, 23, 703.

[2] J. T. Davis, Angew. Chem. 2004, 116, 684; Angew. Chem. Int. Ed. 2004, 43, 668.

[3] W. E. Wright, V. M. Tesmer, K. E. Huffman, S. D. Levene, J. W. Shay, Genes Dev. 1997, 11, 2801.

[4] K. E. Huffman, S. D. Levene, V. M. Tesmer, J. W. Shay, W. E. Wright, J. Biol. Chem. 2000, 275, 19719.

[5] A. J. Zaug, E. R. Podell, T. R. Cech, Proc. Natl. Acad. Sci. USA 2005, 102, 10864

[6] S. Burge, G. N. Parkinson, P. Hazel, A. K. Todd, S. Neidle, Nucleic Acids Res. 2006, 34, 5402.

[7] D. J. Patel, A. T. Phan, V. Kuryavyi, Nucleic Acids Res. 2007, 35, 7429.

[8] J. Dai, M. Carver, D. Yang, Biochimie 2008, 90, 1172.

[9] J. Kypr, I. Kejnovska, D. Renciuk, M. Vorlickova, Nucleic Acids Res. 2009, 37, 1713

[10] Y. Wang, D. J. Patel, Structure 1993, 1, 263.

[11] A. T. Phan, V. Kuryavyi, K. N. Luu, D. J. Patel, Nucleic Acids Res. 2007, 35, 6517.

[12] G. N. Parkinson, M. P. Lee, S. Neidle, Nature 2002, 417, 876.

[13] A. D. Milov, A. B. Ponomarev, Y. D. Tsvetkov, Chem. Phys. Lett. 1984, 110, 67.
[14] R. Ward, D. J. Keeble, H. El Mkami, D. G. Norman, ChemBio Chem 2007, 8, 1957.

[15] J. Dai, M. Carver, C. Punchihewa, R. A. Jones, D. Yang, Nucleic Acids Res. 2007, 35, 4927.

[16] A. Matsugami, Y. Xu, Y. Noguchi, H. Sugiyama, M. Katahira, FEBS J. 2007, 274, 3545.

[17] K. N. Luu, A. T. Phan, V. Kuryavyi, L. Lacroix, D. J. Patel, J. Am. Chem. Soc. 2006, 128, 9963.

[18] A. Ambrus, D. Chen, J. Dai, T. Bialis, R. A. Jones, D. Yang, Nucleic Acids Res. 2006, 34, 2723.

[19] P. Balagurumoorthy, S. K. Brahmachari, J. Biol. Chem. 1994, 269, 21858.

[20] Y. He, R. D. Neumann, I. G. Panyutin, Nucleic Acids Res. 2004, $32,5359$.

[21] L. Ying, J. J. Green, H. Li, D. Klenerman, S. Balasubramanian, Proc. Natl. Acad. Sci. USA 2003, 100, 14629.

[22] A. Risitano, K. R. Fox, Bioorg. Med. Chem. Lett. 2005, 15, 2047.

[23] I. N. Rujan, J. C. Meleney, P. H. Bolton, Nucleic Acids Res. 2005, 33, 2022.

[24] M. Vorlickova, J. Chladkova, I. Kejnovska, M. Fialova, J. Kypr, Nucleic Acids Res. 2005, 33, 5851.

[25] I. Ourliac Garnier, M. A. Elizondo Riojas, S. Redon, N. P. Farrell, S. Bombard, Biochemistry 2005, 44, 10620.

[26] A. Wlodarczyk, P. Grzybowski, A. Patkowski, A. Dobek, J. Phys. Chem. B 2005, 109, 3594.

[27] J. Qi, R. H. Shafer, Nucleic Acids Res. 2005, 33, 3185.

[28] S. Redon, S. Bombard, M. A. Elizondo Riojas, J. C. Chottard, Nucleic Acids Res. 2003, 31, 1605.

[29] J. Li, J. J. Correia, L. Wang, J. O. Trent, J. B. Chaires, Nucleic Acids Res. 2005, 33, 4649.

[30] A. Risitano, K. R. Fox, Nucleic Acids Res. 2004, 32, 2598.

[31] P. Hazel, J. Huppert, S. Balasubramanian, S. Neidle, J. Am. Chem. Soc. 2004, 126, 16405

[32] A. Benz, J. S. Hartig, Chem. Commun. 2008, 4010.

[33] C. Antonacci, J. B. Chaires, R. D. Sheardy, Biochemistry 2007, $46,4654$.

[34] O. Schiemann, N. Piton, Y. Mu, G. Stock, J. W. Engels, T. F. Prisner, J. Am. Chem. Soc. 2004, 126, 5722.

[35] S. Obeid, M. Yulikov, G. Jeschke, A. Marx, Angew. Chem. 2008, 120, 6886; Angew. Chem. Int. Ed. 2008, 47, 6782.

[36] O. Schiemann, N. Piton, J. Plackmeyer, B. E. Bode, T. F. Prisner, J. W. Engels, Nat. Protoc. 2007, 2, 904.

[37] N. Piton, Y. Mu, G. Stock, T. F. Prisner, O. Schiemann, J. W. Engels, Nucleic Acids Res. 2007, 35, 3128.

[38] A. Okamoto, T. Inasaki, I. Saito, Bioorg. Med. Chem. Lett. 2004, 14,3415 .

[39] P. Z. Qin, I. S. Haworth, Q. Cai, A. K. Kusnetzow, G. P. Grant, E. A. Price, G. Z. Sowa, A. Popova, B. Herreros, H. He, Nat. Protoc. 2007, 2, 2354.

[40] G. Z. Sowa, P. Z. Qin, Prog. Nucleic Acid Res. Mol. Biol. 2008, $82,147$.

[41] P. M. Gannett, E. Darian, J. H. Powell, E. M. Johnson, Synth. Commun. 2001, 31, 2137.

[42] O. Frolow, B. E. Bode, J. W. Engels, Nucleosides Nucleotides Nucleic Acids 2007, 26, 655.

[43] P. M. Gannett, E. Darian, J. Powell, E. M. Johnson, 2nd, C. Mundoma, N. L. Greenbaum, C. M. Ramsey, N. S. Dalal, D. E. Budil, Nucleic Acids Res. 2002, 30, 5328.

[44] G. Jeschke, V. Chechik, P. Ionita, A. Godt, H. Zimmermann, J. Banham, C. R. Timmel, D. Hilger, H. Jung, Appl. Magn. Reson. 2006, 30, 473. 